\title{
Butachlor causes disruption of HPG and HPT axes in adult female rare minnow (Gobiocypris rarus)
}

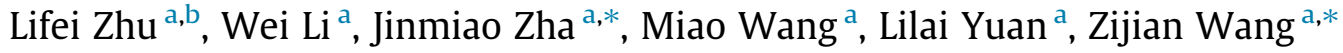 \\ a State Key Laboratory of Environmental Aquatic Chemistry, Research Center for Eco-Environmental Sciences, Chinese Academy of Sciences, P.O. Box 2871, Beijing 100085, China \\ ${ }^{\mathrm{b}}$ Beijing Fishery Research Institute, Beijing 100068, China
}

\section{A R T I C L E I N F O}

\section{Article history:}

Received 7 November 2013

Received in revised form 9 March 2014

Accepted 29 July 2014

Available online 7 August 2014

\section{Keywords:}

Butachlor

Plasma hormone

Hypothalamic-pituitary-gonadal (HPG) axis

Hypothalamic-pituitary-thyroid (HPT) axis Rare minnow (Gobiocypris rarus)

\begin{abstract}
A B S T R A C T
Butachlor is a chloroacetamide herbicide widely used in Asia, and may enter the aquatic environment through agricultural application. In this study, plasma VTG and hormone levels (E2, 11-KT, T3 and T4) were determined after the female rare minnow (Gobiocypris rarus) was exposed to butachlor at environmental relevant concentrations $(0,0.1,1$, and $10 \mu \mathrm{g} / \mathrm{L})$ for 40 days. The mRNA levels of the HPG axis-

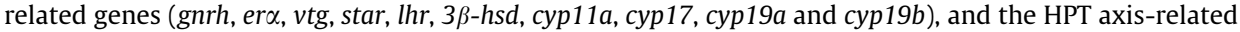
genes (tr $\alpha$, dio1, dio2, and dio3) were quantified after 20 and 40 days exposure to butachlor. For the HPG axis, the plasma 11-KT was increased at exposure concentration of $10 \mu \mathrm{g} / \mathrm{L}$, and VTG was significantly

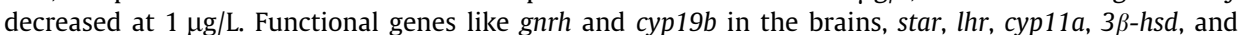
cyp $19 a$ in the ovaries, and $e r \alpha$ and $v t g$ in livers were up-regulated. For the HPT axis, the results showed that plasma T4 levels were significantly increased, the gene expression of dio1 was up-regulated, dio2 showed no significant variation, and dio3 was down-regulated in the livers. These results indicated that butachlor may promote the accumulation of $\mathrm{T} 4$ in fish through inactive deiodinase type 3 . The transcription of HPG axis-related genes could serve as an auto-regulation of hormone levels after exposure to butachlor. Furthermore, the activation of gnrh may play an important role as a feed-back mechanism in the regulation of hormone levels and crosstalk of endocrine axes.
\end{abstract}

(c) 2014 Elsevier Ireland Ltd. All rights reserved.

\section{Introduction}

The use of pesticides in agricultural areas may result in the contamination of surface water and groundwater and also poses a potential risk to aquatic organisms [1,2]. Pesticides have a wide range of acute and chronic health effects, including enzyme inhibition, oxidative damage, inhibition of neurotransmission, abnormal growth and development, and carcinogenic effect [3,4]. Physiological disorders caused by pesticides have been observed in wild fish including abnormal plasma hormone levels, retardant growth of gonads, and delayed sexual maturation $[5,6]$. Several pesticides have been found to be potential endocrine disrupting chemicals (EDCs) and to affect the normal endocrine system function in fish and their offspring $[7,8]$.

Butachlor (2-chloro-2,6-diethyl- $N$-(butoxymethyl)-acetanilide) is a chloroacetamide herbicide that is widely used to control undesired weeds of rice fields in Asia. It is most frequently detected in agricultural soil, surface water, and sediment $[9,10]$. The concentrations of butachlor range from 0.1 to $1.4 \mu \mathrm{g} / \mathrm{L}$ in surface water

\footnotetext{
* Corresponding authors. Tel.: +86 10 62849140; fax: +86 1062929140 (J. Zha). E-mail addresses: jinmiaozha@gmail.com (J. Zha),wangzj@rcees.ac.cn (Z. Wang)
}

[11,12]. Previous investigations showed that butachlor is toxic to aquatic organisms, and the $48 \mathrm{~h}$ LC50 values ranged from 240 to $890 \mu \mathrm{g} / \mathrm{L}$ in fish [13]. Butachlor could induce oxidative stress by depressing the glutathione detoxification system in African catfish (Clarias gariepinus) [14]. Reproductive toxicity, carcinogenicity, genotoxicity and cytotoxicity have also been observed in aquatic organisms or mammalian cell lines after exposure to butachlor [15-17]. Butachlor also affects reproductive success and disrupts the sex and thyroid hormone levels in zebrafish [18]. However, little is known about its toxic mechanisms, especially the regulation of hypothalamic-pituitary-gonad (HPG) and hypothalamic-pituitary-thyroid (HPT) axes at environmental relevant concentrations.

The HPG axis regulates gonadal development and reproduction in fish [19]. The principal HPG axis neurohormone secreted by the hypothalamus is gonadotropin releasing hormone (GnRH). Luteinizing hormone receptor (LHR) has been shown to be expressed in the ovary during sexual maturation [20], and it relays the signal from the pituitary to the gonads to mediate the synthesis of sex steroid hormones [21]. Steroidogenic acute regulatory protein (StAR), which is the rate-limiting step in steroid hormone synthesis, regulates the transfer of cholesterol from the outer to the inner mitochondrial membrane, and has been detected in head kidney, 
gonad and other organs [22]. The cytochrome P450c11 (CYP11A) catalyzes the rate-limiting initial step in steroid biosynthesis, and $3 \beta$-hydroxysteroid dehydrogenase ( $3 \beta$-HSD) is essential for the formation of sex steroids [23]. The cytochrome P450c17 (CYP17) and cytochrome P450c19 (CYP19) are the key enzymes to catalyze androgen biosynthesis, and transforms these androgens to estrogens, respectively [24]. Estrogens induce vitellogenin (VTG) production in the liver of fish through binding to estrogen receptors (ERs) [25]. Moreover, The HPT axis is responsible for maintaining homeostasis of the thyroid hormone (THs) by regulating the synthesis, secretion, transport and metabolism in teleosts. Iodothyronine deiodinases are important regulators of thyroid hormone action in teleosts $[26,27]$. Three deiodinases have been found in fish: type 1 (Dio1), type 2 (Dio2), and type 3 (Dio3), which control the conversion of T4 to the more active T3 or to the inactive metabolites rT3 and T2 [28]. The biological activity of THs are mediated by TH receptors (TRs) in fish [29]. Exposure to some EDCs can affect the hormones regulation of HPG or HPT axes and lead to a disturbance of hormone metabolism, hormone-regulated cellular or physiological processes in fish. Due to its small size, ease of culture, short life cycle and prolific egg production with high fertilization and hatching rates, rare minnow (Gobiocypris rarus) is considered to be an ideal model fish in the laboratory and an appropriate species for the assessment of endocrine-disrupting chemicals [30]. In this study, we detected the changes and regulation of gnrh, star, $3 \beta$-hsd, lhr, cyp11a, cyp17, cyp19a, cyp19b, er $\alpha$, and vtg genes mRNA levels in the HPG axis, and tro, dio1, dio2, and dio3 in the HPT axis of female rare minnow. Our studies aimed to examine the toxicity of butachlor in terms of growth, tissue indices, histological analysis, hormone levels, and mRNA expressions of HPG and HPT axes to elucidate the possible molecular mechanisms underlying toxic responses.

\section{Materials and methods}

\subsection{Chemicals}

Butachlor was purchased from Sigma-Aldrich Chemical Co. (USA). A stock solution of butachlor was prepared by dilution in HPLC-grade acetone. Working solutions were freshly diluted by the stock solutions with dechlorinated tap water. To obtain the final concentration for exposure, an appropriate amount of the solutions were added to the aquarium water via polytetrafluorethylene (PFTE) and isoversinic tubes (Abimed, Langenfeld, Germany). The solutions were mixed in vessels with the aquarium water, which flowed through the exposure chambers $(18 \mathrm{~L})$ at a rate of $4 \mathrm{~L} / \mathrm{h}$. The final concentration of acetone in the aquarium water was less than $0.001 \%$.

\subsection{Culture conditions and experimental design}

The brood stock of rare minnow was raised in flow-through system with dechlorinated tap water $(\mathrm{pH} 7.2-7.6$; hardness 44.0-61.0 $\mathrm{mg} \mathrm{CaCO} / \mathrm{L})$ at a constant temperature $\left(25 \pm 1{ }^{\circ} \mathrm{C}\right)$ with a photoperiod of $16: 8 \mathrm{~h}$ (light:dark) and has been used for testing chemicals in our laboratory for more than nine years. Fish were fed with a commercial pellet food (Tetra, Germany) at a rate of $0.1 \%$ body weight per day and with newly hatched brine shrimp (Artemia) nauplii twice daily. Waste and residue were removed daily, and the test equipment and chambers were cleaned once a week.

Healthy five-month old adult female rare minnows that were offspring from the same pair of brood stock were randomly divided into four groups (30 fish in each group). Fish were exposed under flow-through conditions to various concentrations (control, 0.1,
1 , and $10 \mu \mathrm{g} / \mathrm{L}$; nominal concentrations) of butachlor for 40 days; each treatment was conducted in triplicate. After 20 days of exposure, liver and ovary samples were taken in each group for isolation of total RNA (5 females). The remaining fish in each group were euthanized after 40 days of exposure. The blood was collected from each fish with a heparinized microcapillary tube and centrifuged immediately at $8000 \times \mathrm{g}$ for $10 \mathrm{~min}$ at $4{ }^{\circ} \mathrm{C}$ and the plasma stored at $-80{ }^{\circ} \mathrm{C}$ until analysis. The ovary and liver of each fish were removed and weighed after the blood was collected. The gonadosomatic index (GSI) and hepatosomatic index (HSI) were calculated as following: GSI = gonad weight $(\mathrm{g}) /$ body weight $(\mathrm{g}) \times 100$; HSI $=$ liver weight $(\mathrm{g}) /$ bodyweight $(\mathrm{g}) \times 100$. In addition, the brains, livers and ovaries were flash-frozen in liquid nitrogen and stored at $-80^{\circ} \mathrm{C}$ until RNA extraction.

\subsection{Histological analysis}

The liver and ovary were fixed in Bouin's solution, dehydrated and processed for paraffin wax embedding. Sections were cut at 3-4 $\mu \mathrm{m}$ and stained with hematoxylin and eosin (H\&E). Five randomly selected separate nonoverlapping microscopic fields were examined with a Zeiss Axioskop 2 mot plus microscope, and the digital images were viewed using Axiovision LE Version software. For ovary analysed, 100 oocytes were scored and the proportion of oocytes at different stage of perinucleolar oocytes, cortical alveolar oocytes, and vitellogenic oocytes calculated.

\subsection{Plasma vitellogenin and hormone levels measurement}

Plasma vitellogenin (VTG), 17 $\beta$-estradiol (E2), 11-ketotestosterone (11-KT), and thyroid hormones (T3 and T4) were measured using the enzyme-linked immunosorbent assay (ELISA) kits (Shanghai Hufeng Chemical Industry Co., China), according to the manufacturer's instructions. All samples were analyzed in duplicate, and a separate standard curve was run for each ELISA plate. The assay detection limits were $30 \mathrm{ng} / \mathrm{mL}$ for VTG, $1.5 \mathrm{pg} / \mathrm{mL}$ for E2, $7.0 \mathrm{pg} / \mathrm{mL}$ for $11-\mathrm{KT}, 0.65 \mathrm{ng} / \mathrm{mL}$ for T3, and $1.5 \mathrm{ng} / \mathrm{mL}$ for T4, respectively. All samples were measured at $450 \mathrm{~nm}$ using a Tecan infinite M200 plate reader.

\subsection{RNA-isolation and reverse transcription}

The total RNA was isolated from the brains, livers and ovaries ( 5 female fish) using the TRNzol- $\mathrm{A}^{+}$reagent (TIANGEN, Beijing, China) and the manufacturer's protocol. Traces of DNA were removed by incubation with DNase-I (Promega, Madison, WI, USA). Then RNA samples were dissolved in ribonuclease-free water and stored at $-80^{\circ} \mathrm{C}$. The reverse transcription reaction mixtures containing $10 \mu \mathrm{L}$ of total RNA and $2 \mu \mathrm{L}(0.05 \mu \mathrm{g} / \mu \mathrm{L})$ of Oligo(dT) 15 primers were heated to $70{ }^{\circ} \mathrm{C}$ for $5 \mathrm{~min}$ and quickly chilled on ice. After cooling, 40 units of RNasin (RNase inhibitor; Promega), $200 \mathrm{U}$ of Avian Myeloblastosis Virus Reverse Transcriptase (Promega), and buffer (Promega) were added to a total volume of $25 \mu \mathrm{L}$ and incubated for $1 \mathrm{~h}$ at $37^{\circ} \mathrm{C}$. Thereafter, the reaction mixture was heated to $70{ }^{\circ} \mathrm{C}$ for $10 \mathrm{~min}$ to inactivate the reverse transcription.

\subsection{Real-time PCR}

Real-time PCR was performed in a MX3005P real-time quantitative polymerase chain reaction system (Stratagene, USA) in a total volume of $25 \mu \mathrm{L}$ consisting of the Brilliant II SYBR Green QPCR master mix, $300 \mathrm{nM}$ forward primer and $300 \mathrm{nM}$ reverse primer. The forward and reverse primers used and PCR products are listed in Table A.1. The thermal cycle parameters used were $10 \mathrm{~min}$ at $95{ }^{\circ} \mathrm{C}, 40$ cycles of $30 \mathrm{~s}$ at $95^{\circ} \mathrm{C}, 30 \mathrm{~s}$ at $57^{\circ} \mathrm{C}$, and $30 \mathrm{~s}$ at $72{ }^{\circ} \mathrm{C}$. All the samples were analyzed in triplicate, and the mean value of 
these triplicate measurements were used for calculations of mRNA expressions in different tissues. Results were analyzed according to

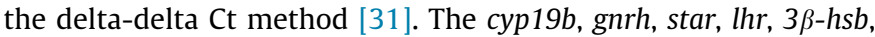
cyp11a, cyp17, cyp19a, tra, dio1, dio2, dio3, er $\alpha$ and vtg mRNA expressions were normalized for $\beta$-actin mRNA expression. Dissociation curve analysis was performed for each gene to check the amplification of untargeted fragments. Only one peak was observed for each amplification, indicative of the amplification of the target gene only. Gene expression data are presented as the fold change relative to control fish within the same treatment period.

\subsection{Statistics}

All statistical analyses were performed with the SPSS (version 16.0; USA). All quantitative data were expressed as the mean \pm SEM. A statistical analysis of the data was performed using analysis of variance, followed by Bonferroni's multiple comparison Test. A probability of $p<0.05$ was considered statistically significant, and $p<0.01$ was considered highly statistically significant.

\section{Results}

\subsection{Mortality and growth}

During the exposure period, mortality and malformation were not observed in the control and treatments. The body length was significantly decreased only at an exposure concentration of $10 \mu \mathrm{g} / \mathrm{L}$ (Table 1). There were no statistically differences in the HSI and GSI between the control and treatments.

\subsection{Histological analysis}

Several pathological changes were observed in the livers and ovaries of fish after butachlor exposure (Fig. 1). The hepatocytes of control fish were compactly arranged (Fig. 1A). However, the hepatic tissue displayed disordered hepatocyte arrangement and vacuoles in the cytoplasm, cytoplasm degeneration and irregular nuclear shapes were observed in the $10 \mu \mathrm{g} / \mathrm{L}$ treatment group (Fig. 1B). The ovaries of control rare minnow showed in process of gametogenesis with generations of ova in different developmental stages, and contained vitellogenic oocytes (17\%), cortical alveolus stages (32\%) and perinucleolar oocytes (30\%) (Fig. 1C). In comparison, the major oocytes were vitellogenic oocytes $(22 \%)$ and cortical alveolus stages (64\%), and lower proportion of perinucleolar oocytes (14\%) was observed at $10 \mu \mathrm{g} / \mathrm{L}$ (Fig. 1D).

\subsection{Plasma vitellogenin and hormone levels}

At the end of the exposure period, plasma VTG levels were significantly decreased at $1 \mu \mathrm{g} / \mathrm{L}$ (Fig. 2). There was no significant difference in the plasma E2 and T3 levels between treatment and control groups, whereas plasma 11-KT and T4 levels were significantly increased in the $10 \mu \mathrm{g} / \mathrm{L}$ treatment group after 40 days of exposure to butachlor $(p<0.05)$.

\section{Table 1}

Growth, gonadosomatic index (GSI) and hepatosomatic somatic index (HSI) of female rare minnow after 40 days of exposure.

\begin{tabular}{lllll}
\hline Con. $(\mu \mathrm{g} / \mathrm{L})$ & Length $(\mathrm{mm})$ & Weight $(\mathrm{g})$ & GSI $(\%)$ & HSI $(\%)$ \\
\hline Control & $48.32 \pm 3.16$ & $1.36 \pm 0.30$ & $17.95 \pm 3.52$ & $1.95 \pm 0.37$ \\
0.1 & $46.84 \pm 3.26$ & $1.26 \pm 0.33$ & $18.83 \pm 6.23$ & $2.35 \pm 0.43$ \\
1 & $47.89 \pm 3.36$ & $1.32 \pm 0.32$ & $18.04 \pm 6.33$ & $2.34 \pm 0.22$ \\
10 & $45.51 \pm 2.71^{*}$ & $1.17 \pm 0.27$ & $17.42 \pm 6.55$ & $2.13 \pm 0.62$ \\
\hline
\end{tabular}

Data expressed as mean \pm SEM of each treatment $(n=15)$.

"Significantly different from the controls $(p<0.05)$.

\subsection{Quantitation of genes mRNA in the brains}

The expression of cyp $19 \mathrm{~b}$ and gnrh mRNA levels in the brains of female fish was determined after 20 and 40 days of exposure to butachlor (Fig. 3). The mRNA levels of cyp19b genes were significantly up-regulated for all the treatment groups after 20 days of exposure $(p<0.05)$, whereas there was no significant difference in gnrh mRNA levels between the treatment and control groups. At the end of exposure, the up-regulation of cyp $19 \mathrm{~b}$ and gnrh mRNA levels was observed in the brains only in the $10 \mu \mathrm{g} / \mathrm{L}$ treatment group $(p<0.01)$

\subsection{Quantitation of genes $m R N A$ in the ovaries}

The expressions of star, lhr, 3ß-hsd, cyp11a, cyp17, and cyp19a mRNA levels in the ovaries of female fish was determined after 20 and 40 days of exposure to butachlor (Fig. 4). The mRNA levels

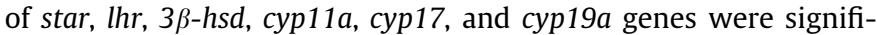
cantly up-regulated for all the treatment groups after 20 days of exposure. After 40 days of exposure, the up-regulation of star, $l \mathrm{hr}$, $3 \beta$-hsd, cyp $11 a$, and cyp19a was observed in the ovaries only at $10 \mu \mathrm{g} / \mathrm{L}$, whereas the down-regulation of cyp17 was observed at 0.1 and $1 \mu \mathrm{g} / \mathrm{L}$.

\subsection{Quantitation of genes $m R N A$ in the livers}

The expression of tro, dio1, dio2, dio3, er $\alpha$, and $v \operatorname{tg}$ mRNA levels in the livers of female rare minnow was determined after 20 and 40 days of exposure to butachlor (Fig. 5). The mRNA levels of tra and dio3 genes were significantly down-regulated for all the treatment groups after 20 days of exposure, whereas the expression of dio1, er $\alpha$, and $v \operatorname{tg}$ mRNA levels was significantly up-regulated after 20 days of exposure. There was no significant difference in the expression of dio2 mRNA levels compared with the control after 20 and 40 days of exposure. At the end of exposure, the up-regulation of dio1 and er $\alpha$ was observed in the livers of female in the treatment groups exposed to more than $1 \mu \mathrm{g} / \mathrm{L}$, whereas the down-regulation of dio3 was observed at $10 \mu \mathrm{g} / \mathrm{L}$. Moreover, there were no significant changes in the tr $\alpha$ mRNA levels after 40 days of exposure. The expression of $v t g$ mRNA levels was still significantly up-regulated at all treatment groups after 40 days of exposure.

\section{Discussion}

The chloroacetamide herbicides include acetochlor, metolachlor, alachlor and butachlor. Some of chloroacetamide herbicides have been confirmed to possess endocrine disrupting properties [32]. For example, acetochlor significantly down-regulates thyroid hormone related genes in larval and tissue-specific alternative expressions in adult rare minnow [33], and metolachlor exposure has been demonstrated to disrupt the thyroid system in medaka [34]. Butachlor has a chemical structure, properties and metabolites that are similar to other chloroacetamide herbicides [35,36]. In this study, the effects of environmentally relevant concentrations of butachlor on the histological changes in the livers and gonads, plasma VTG and hormone levels, and expressions of HPG and HPT axis-related genes mRNA levels were investigated in adult female rare minnow under laboratory conditions.

In this study, no mortality or malformation was observed throughout the experimental period. However, the body lengths of fish at $10 \mu \mathrm{g} / \mathrm{L}$ were less than controls after 40 days of exposure. Regarding growth, the toxic threshold of butachlor should be approximately $10 \mu \mathrm{g} / \mathrm{L}$, or at environmental levels. In previous work, exposure to butachlor at $100 \mu \mathrm{g} / \mathrm{L}$ did not affect the HSI or GSI of female zebrafish after 30 days [18], and our results also 

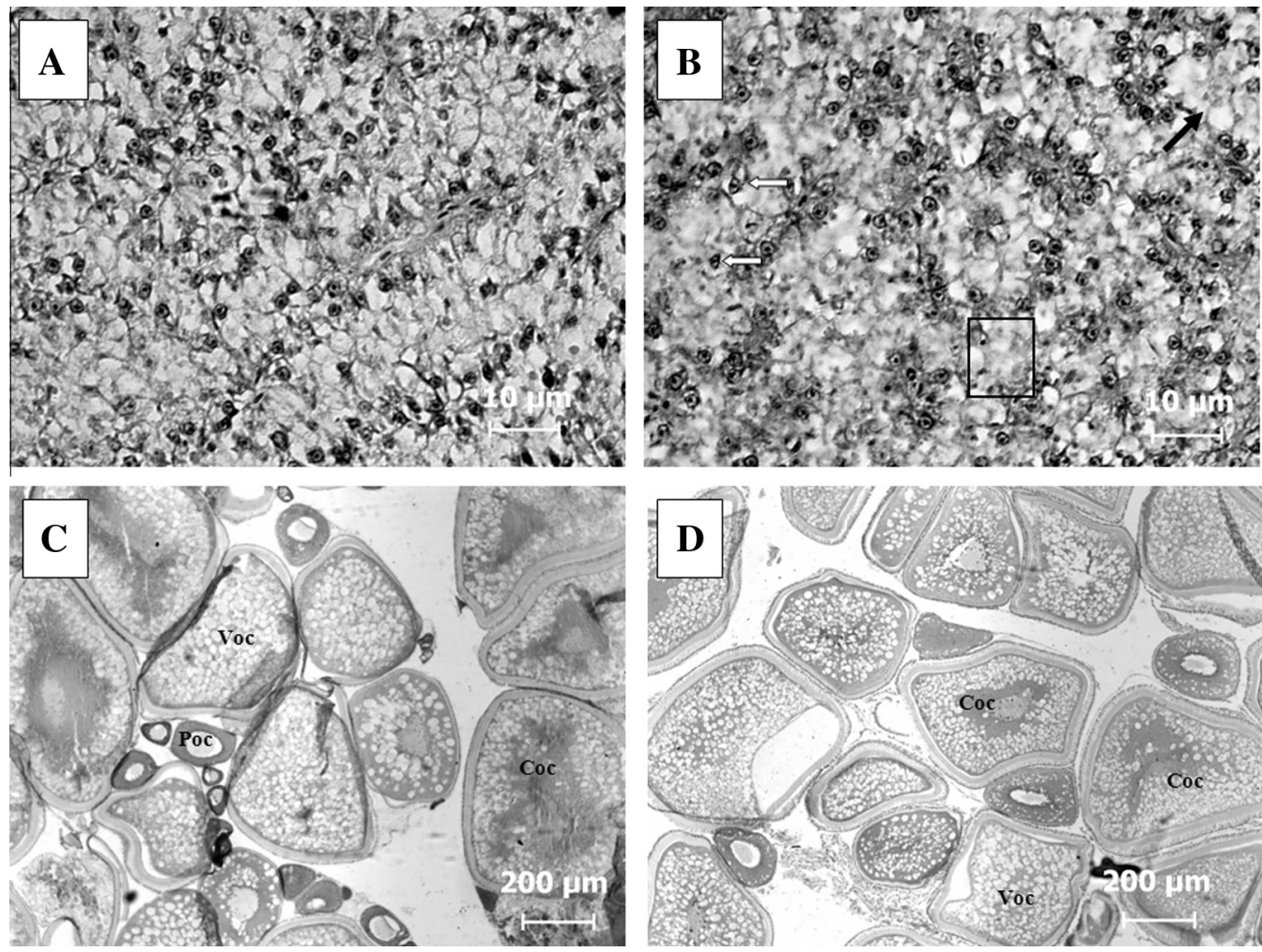

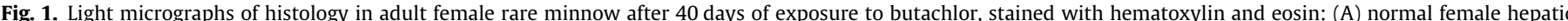

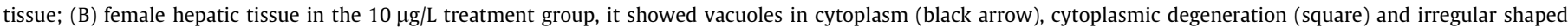

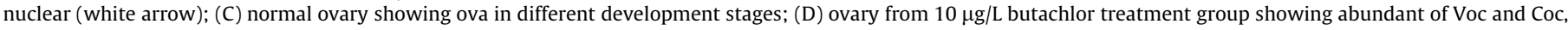
and limited number of Poc. Voc, vitellogenic oocyte; Coc, cortical alveolus stage; Poc, perinucleolar oocyte.

showed that exposure to butachlor below $10 \mu \mathrm{g} / \mathrm{L}$ did not affect the HSI or GSI of female rare minnow after 40 days. The histopathological assessment of fish tissue has been used as a warning sign for diseases caused by exposure to environmental pollutions $[37,38]$. As shown in Fig. 1, vacuoles in the cytoplasm, cytoplasmic degeneration and irregular nuclear shapes were observed in the livers. Meanwhile a decrease in primary growth oocytes and an increase in maturing oocytes were observed at the $10 \mu \mathrm{g} / \mathrm{L}$ in the ovaries. These results suggested that butachlor could induce hepatic tissue damage and potentially have adverse effects on the fertility of the fish.

Moreover, sex steroid hormones play an important role in sex differentiation, sexual development, and normal reproduction in fish $[39,40]$. In the present study, plasma 11-KT levels were significantly increased in the $10 \mu \mathrm{g} / \mathrm{L}$ treatment group. There was a slight increase of plasma E2 in the exposure groups, but the increase was not statistically significant between the exposure and control groups. Previous studies have demonstrated that alachlor and acetochlor may partially mimic the primary endogenous estrogen and bind to estrogen receptors (ERs) [41,42]. According to these results, butachlor might imitate the function of estrogen in fish and lead to potential accumulation of E2. Moreover, estrogens induce vitellogenin (VTG) production in the liver of fish by binding to ERs and exerting its full biological effects [43]. In the current study, plasma VTG levels were significantly decreased in the $1 \mu \mathrm{g} / \mathrm{L}$ treatment group. It is reported that hepatically produced VTG is transported via the bloodstream and sequestered by the developing oocytes [44]. Whatever, the decrease of plasma VTG might be caused by the consumption during ova development. The up-regulation of er $\alpha$ and $v \operatorname{tg}$ mRNA levels was observed in all treatment groups after 20 and 40 days of exposure in the livers. It is reported that the expression of er $\alpha$ and $v t g$ demonstrated a significant relationship after E2 exposure in the liver of mud carp [45]. In female zebrafish, the increase of plasma E2 was accompanied by up-regulated hepatic er $\alpha$ and $v$ tg expression after exposure to fluorotelomer alcohol (6:2 FTOH) [46]. Therefore, the present data suggested that butachlor could disrupt the sex steroid hormonal balance and function in fish at environmentally relevant concentrations.

Sex steroid hormones, testosterone and $17 \beta$-estradiol are produced from cholesterol through a series of reactions. The ovaries play a main role in producing steroid hormones for sexual and reproductive functions, as well as eggs produced for fertilization [47]. In the present study, the mRNA levels of star, $l h r, 3 \beta$-hsd, cyp11a, cyp17, and cyp19a in the ovaries, and cyp19b in the brains were significantly up-regulated for all the treatment groups after 20 days of exposure. The significant up-regulation of mRNA levels was observed only in the $10 \mu \mathrm{g} / \mathrm{L}$ treatment group after 40 days of exposure, not including cyp17, which was down regulated in the low-dose groups. Similarly, the expression of cyp $19 b$ was significantly increased after the exposure of zebrafish larvae to $10 \mathrm{nM}$ E2 [48]. The patterns of HPG axis gene expression suggested that butachlor may disrupt the sex steroid steroids synthesis of aquatic organisms at environmentally relevant concentrations.

THs are essential for the developmental and physiological functions in vertebrates. The plasma T4 levels at $10 \mu \mathrm{g} / \mathrm{L}$ were significantly higher than those of the control after butachlor exposure. Previous studies have shown that plasma T3 and T4 concentrations were increased after exposure to $100 \mu \mathrm{g} / \mathrm{L}$ butachlor in female zebrafish after 30 days of exposure [18]. Our data demonstrated that the up-regulation of dio1 and down-regulation of dio3 were observed in the livers, whereas there was no significant difference in the expression of dio2 mRNA levels of females after 20 and 40 days of exposure. Similar results were obtained from the tail 

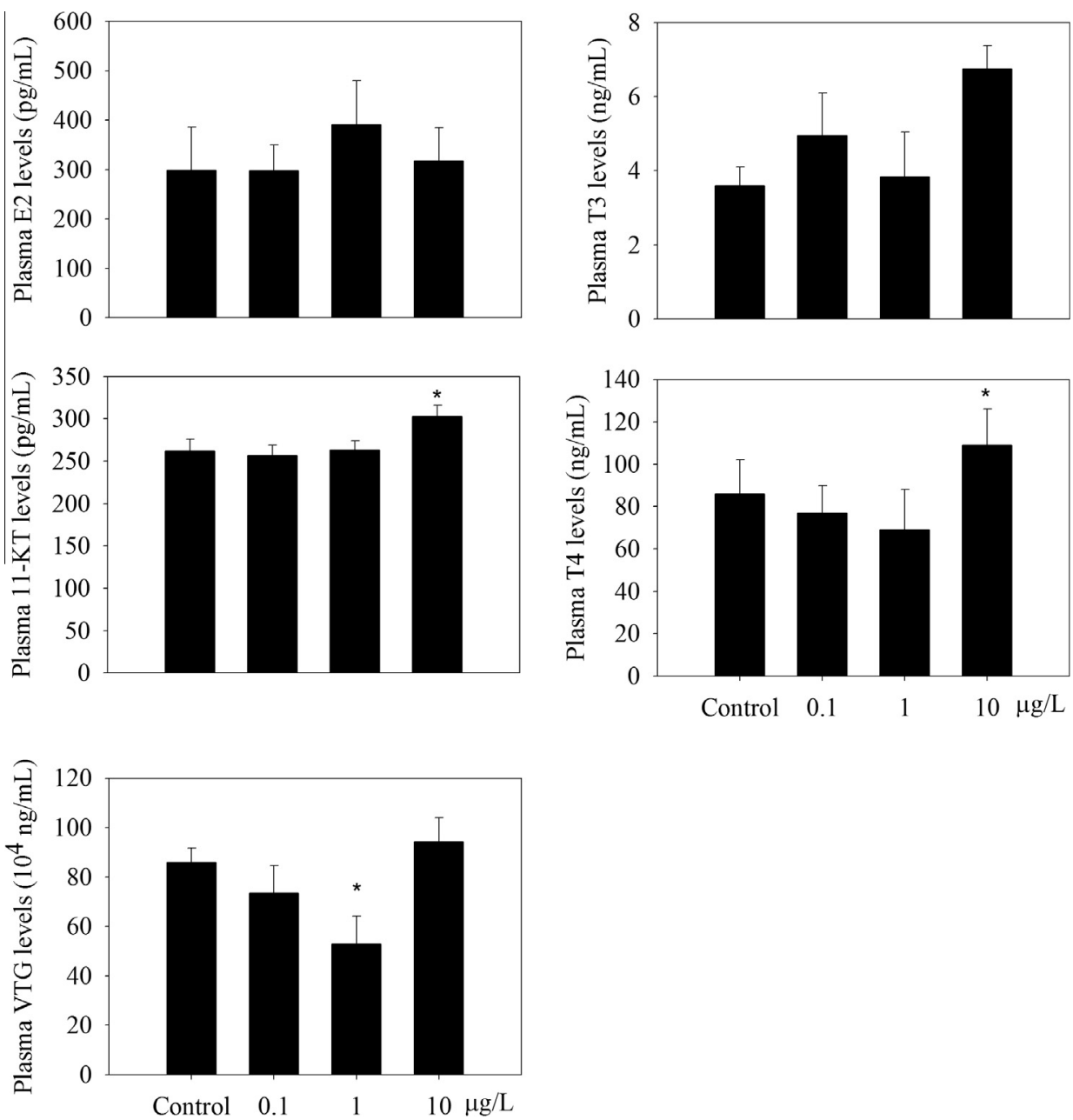

Fig. 2. Plasma concentrations of hormone levels and vitellogenin after 40 days of exposure in female rare minnow.
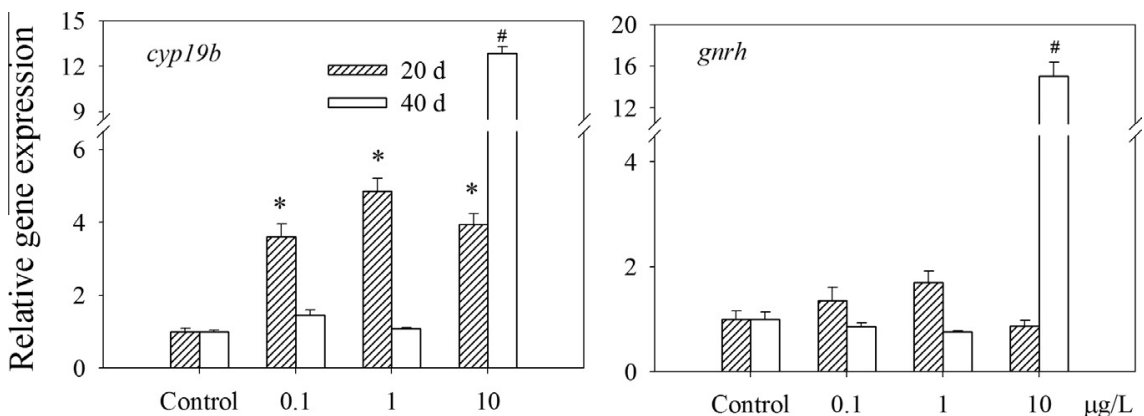

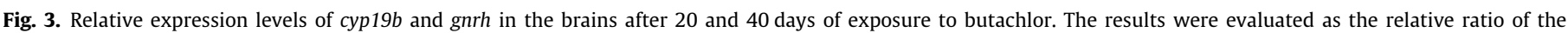
expression level of each mRNA to that of $\beta$-actin. ${ }^{*} p<0.05$, ${ }^{*} p<0.01$, relative to control.

tissue of Xenopus laevis tadpoles after acetochlor $(10 \mathrm{nM})$ treatment, the hormone-dependent increase of dio3 expression was decreased, and there was no effect on the expression of dio2 mRNA [49]. The biological activity of THs is predominantly mediated at the level of gene expression by binding to $\mathrm{TH}$ receptors in fish. Our results showed that a down-regulation of tr $\alpha$ mRNA levels occurred after 20 days of exposure but returned back to their normal levels, similar to those of control, at the end of exposure. As was previously reported, acetochlor does not bind to human TR $\beta$ [50]. Taken together, these results indicated that butachlor could disrupt the homeostasis of THs via non-receptor pathway. The accumulation of T4 in fish may be due to inhibit inner deiodination through inactive deiodinase type 3.

The HPG axis is the primary regulator of the mature reproductive system, and consists of neurons in the hypothalamus that secrete gonadotropin releasing hormone $(\mathrm{GnRH})$. The expression of gnrh has been implicated in hypophysiotropic functions, development, and sexual behavior [51]. Previous studies indicated that there was a correlation between thyroid activity and $\mathrm{GnRH}$ levels [52]. In the present study, T4 and gnrh mRNA levels were up-regulated in the $10 \mu \mathrm{g} / \mathrm{L}$ treatment group after 40 days of exposure in the plasma and brain, respectively. It has been reported that 

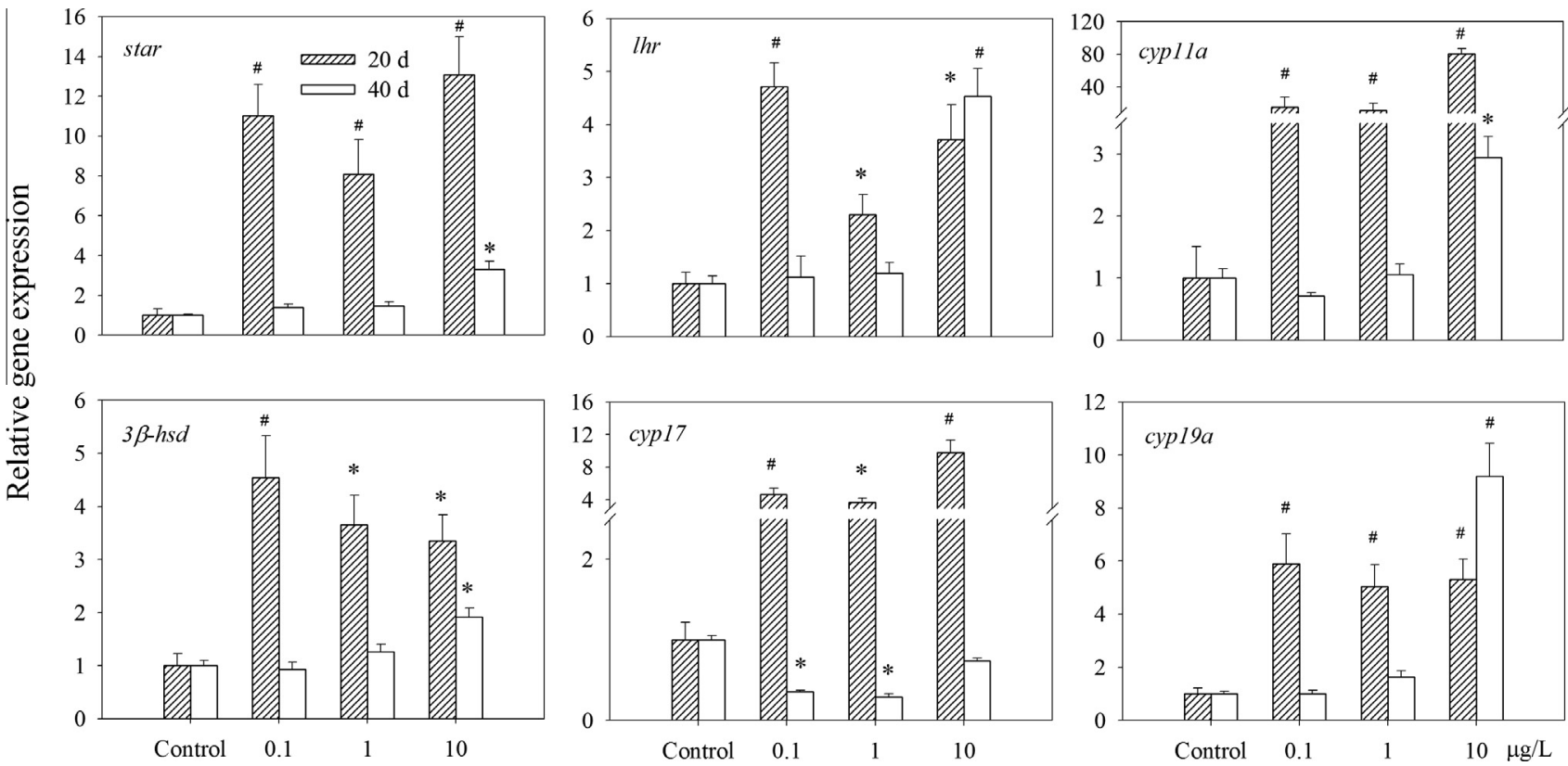

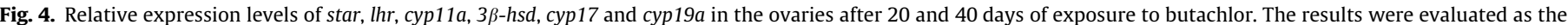
relative ratio of the expression level of each mRNA to that of $\beta$-actin. ${ }^{*} p<0.05$, ${ }^{\#} p<0.01$, relative to control.
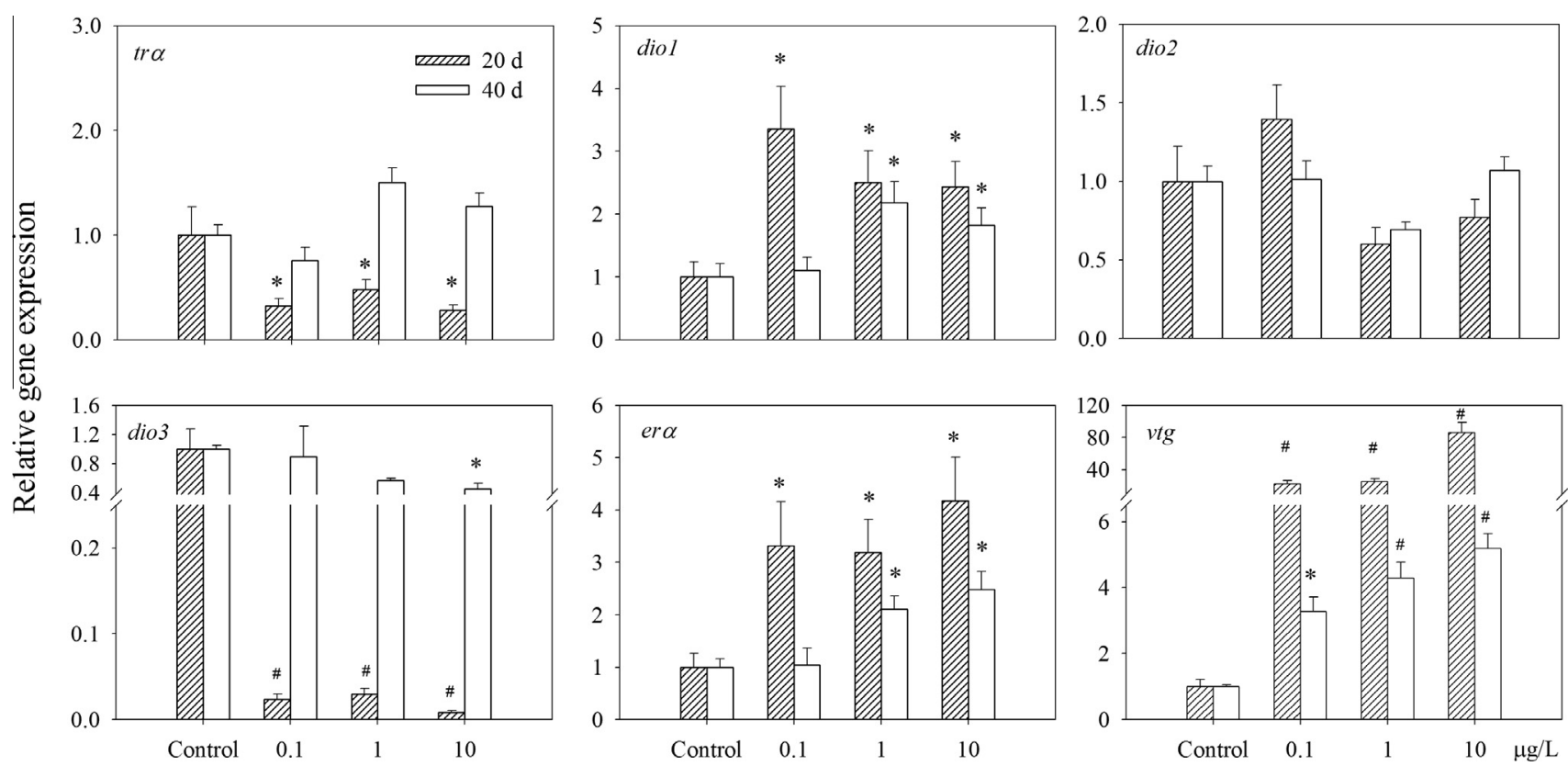

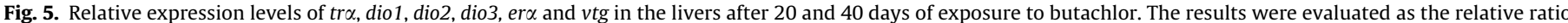
of the expression level of each mRNA to that of $\beta$-actin. ${ }^{*} p<0.05,{ }^{*} p<0.01$, relative to control.

gnrh3 was significantly up-regulated in the brains of female rare minnow, whereas ovarian P450 aromatase was down-regulated in the $15 \mu \mathrm{g} / \mathrm{L}$ bisphenol A (BPA) concentration group after 35 days of exposure [53]. One possible explanation for the regulation between the HPT and HPG axes could be that the increase of T4 initiates the transcription of gnrh through the feed-back mechanism, which leads to alternation of sex hormone metabolism. The activation of gnrh results in changes in hormone levels and the transcription of HPG-related genes. The present data suggested that the activation of gnrh may play an important role as a feed-back mechanism in the regulation of hormone levels and in the crosstalk between endocrine axes. Moreover, the THs may also play critical roles in normal reproduction, sex steroids levels, and expression of steroidogenic enzyme genes [54]. The previous studies have demonstrated that T4 administration in female catfish enhanced the growth rate of ovarian follicles and entry of oocytes into the maturational phase compared with controls in the preparatory phase [55]. In the present study, the increase of maturing oocytes accompanied by an increased in plasma T4 were also observed in the $10 \mu \mathrm{g} / \mathrm{L}$ treatment group. The mRNA levels of HPT or HPG axis-related gene were returned to the control levels at lower treatment groups after 40 days of exposure, which might indicate a self-adjustment of endocrine system in fish to butachlor exposure. Overall, the mechanisms for the endocrine system involve 
complex arrangements of interacting axes, which are largely unknown and will require further experimentation.

\section{Conclusion}

In this study, the histological changes, plasma VTG, hormone levels, and the expressions of HPG and HPT axis-related gene mRNA levels were determined in adult female rare minnow after exposure to butachlor. The results indicated that butachlor could induce hepatic tissue damage and potentially have adverse effects on fertility of the fish at the tissue levels. Sex steroid synthesis, homeostasis, and regulation of the HPG axis could be disrupted in the fish. Butachlor may disrupt the thyroid hormonal balance of HPT axis via inactive deiodinase type 3. The activation of gnrh may play an important role as a feed-back mechanism in the regulation of hormone levels and the transcription of HPG-related genes. However, further studies should be performed with lowdose longer exposure to study the interaction between the endocrine axes.

\section{Conflict of Interest}

The authors declare that there are no conflicts of interest.

\section{Transparency Document}

The Transparency document associated with this article can be found in the online version.

\section{Acknowledgements}

This work was supported by the National Natural Science Foundation of China (51290283; 21407166; 21007086); the National High-tech R\&D Program (2012AA06A302).

\section{Appendix A. Supplementary data}

Supplementary data associated with this article can be found, in the online version, at http://dx.doi.org/10.1016/j.cbi.2014.07.016.

\section{References}

[1] J.F. Carriger, G.M. Rand, Aquatic risk assessment of pesticides in surface waters in and adjacent to the Everglades and Biscayne National Parks: II. Probabilistic analyses, Ecotoxicology 17 (7) (2008) 680-696.

[2] S.A.-M.-A.-S. Eqani, R.N. Malik, A. Cincinelli, G. Zhang, A. Mohammad, A. Qadir A. Rashid, H. Bokhari, K.C. Jones, A. Katsoyiannis, Uptake of organochlorine pesticides (OCPs) and polychlorinated biphenyls (PCBs) by river water fish: the case of River Chenab, Sci. Total Environ. 450 (2013) 83-91.

[3] M.C. Alavanja, M.R. Bonner, Occupational pesticide exposures and cancer risk: a review, J. Toxicol. Environ. Health B 15 (4) (2012) 238-263.

[4] C.J. Burns, L.J. McIntosh, P.J. Mink, A.M. Jurek, A.A. Li, Pesticide exposure and neurodevelopmental outcomes: review of the epidemiologic and animal studies, J. Toxicol. Environ. Health B 16 (3-4) (2013) 127-283.

[5] D.H. Baldwin, J.A. Spromberg, T.K. Collier, N.L. Scholz, A fish of many scales: extrapolating sublethal pesticide exposures to the productivity of wild salmon populations, Ecol. Appl. 19 (8) (2009) 2004-2015.

[6] N. Mayon, A. Bertrand, D. Leroy, C. Malbrouck, S. Mandiki, F. Silvestre, A. Goffart, J.-P. Thomé, P. Kestemont, Multiscale approach of fish responses to different types of environmental contaminations: a case study, Sci. Total Environ. 367 (2) (2006) 715-731.

[7] R.H. Da Cuna, M. Pandolfi, G. Genovese, Y. Piazza, M. Ansaldo, F.L.L. Nostro, Endocrine disruptive potential of endosulfan on the reproductive axis of Cichlasoma dimerus (Perciformes, Cichlidae), Aquat. Toxicol. 126 (2012) 299305.

[8] B. Lal, M.K. Sarang, P. Kumar, Malathion exposure induces the endocrine disruption and growth retardation in the catfish, Clarias batrachus (Linn), Gen. Comp. Endocrinol. 181 (2012) 139-145.

[9] R. Shi, J. Lv, J. Feng, Assessment of pesticide pollution in suburban soil in south Shenyang, China, Bull. Environ. Contam. Toxicol. 87 (5) (2011) 567-573.
[10] P.V. Toan, Z. Sebesvari, M. Bläsing, I. Rosendahl, F.G. Renaud, Pesticide management and their residues in sediments and surface and drinking water in the Mekong Delta, Vietnam, Sci. Total Environ. 452 (2013) 28-39.

[11] M. Mamun, I. Rouf, J.H. Park, J.H. Choi, H.K. Kim, W.J. Choi, S.S. Han, K. Hwang, N.I. Jang, M.E. Assayed, Development and validation of a multiresidue method for determination of 82 pesticides in water using GC, J. Sep. Sci. 32 (4) (2009) 559-574.

[12] X.-B. Yang, G.-G. Ying, R.S. Kookana, Rapid multiresidue determination for currently used pesticides in agricultural drainage waters and soils using gas chromatography-mass spectrometry, J. Environ. Sci. Health B 45 (2) (2010) $152-161$.

[13] Y.-S. Wang, C.-G. Jaw, H.-C. Tang, T.-S. Lin, Y.-L. Chen, Accumulation and release of herbicides butachlor, thiobencarb, and chlomethoxyfen by fish, clam, and shrimp, Bull. Environ. Contam. Toxicol. 48 (3) (1992) 474-480.

[14] E.O. Farombi, Y.R. Ajimoko, O.A. Adelowo, Effect of Butachlor on antioxidant enzyme status and lipid peroxidation in fresh water African Catfish, (Clarias gariepinus), Int. J. Environ. Res. Public Health 5 (5) (2008) 423-427.

[15] B. Ateeq, M. Abul farah, M. Niamat Ali, W. Ahmad, Induction of micronuclei and erythrocyte alterations in the catfish Clarias batrachus by 2,4dichlorophenoxyacetic acid and butachlor, Mutat. Res. 518 (2) (2002) 135144.

[16] M. Junghans, T. Backhaus, M. Faust, M. Scholze, L.H. Grimme, Predictability of combined effects of eight chloroacetanilide herbicides on algal reproduction, Pest Manag. Sci. 59 (10) (2003) 1101-1110.

[17] Y.H. Ou, P.C. Chung, Y.-C. Chang, F.Q. Ngo, K.-Y. Hsu, F.-D. Chen, Butachlor, a suspected carcinogen, alters growth and transformation characteristics of mouse liver cells, Chem. Res. Toxicol. 13 (12) (2000) 1321-1325.

[18] J. Chang, S. Liu, S. Zhou, M. Wang, G. Zhu, Effects of butachlor on reproduction and hormone levels in adult zebrafish (Danio rerio), Exp. Toxicol. Pathol. 65 (12) (2011) 205-209.

[19] Y.G. Piazza, M. Pandolfi, F.L.L. Nostro, Effect of the organochlorine pesticide endosulfan on GnRH and gonadotrope cell populations in fish larvae, Arch. Environ. Contam. Toxicol. 61 (2) (2011) 300-310.

[20] D. Crespo, E.L. Mañanós, N. Roher, S.A. MacKenzie, J.V. Planas, Tumor necrosis factor alpha may act as an intraovarian mediator of luteinizing hormoneinduced oocyte maturation in trout, Biol. Reprod. 86 (1) (2012) 1-12.

[21] L.S. Huffman, M.M. Mitchell, L.A. O'Connell, H.A. Hofmann, Rising StARs: behavioral, hormonal, and molecular responses to social challenge and opportunity, Horm. Behav. 61 (4) (2012) 631-641.

[22] B.S. Nunez, A.N. Evans, Hormonal regulation of the steroidogenic acute regulatory protein (StAR) in gonadal tissues of the Atlantic croaker (Micropogonias undulatus), Gen. Comp. Endocrinol. 150 (3) (2007) 495-504.

[23] R.-L. Wang, D. Bencic, J. Lazorchak, D. Villeneuve, G.T. Ankley, Transcriptional regulatory dynamics of the hypothalamic-pituitary-gonadal axis and its peripheral pathways as impacted by the 3-beta HSD inhibitor trilostane in zebrafish (Danio rerio), Ecotoxicol. Environ. Saf. 74 (6) (2011) 1461-1470.

[24] T. Uno, M. Ishizuka, T. Itakura, Cytochrome P450 (CYP) in fish, Environ. Toxicol. Pharmacol. 34 (1) (2012) 1-13.

[25] E.R. Nelson, H.R. Habibi, Functional significance of nuclear estrogen receptor subtypes in the liver of goldfish, Endocrinology 151 (4) (2010) 1668-1676.

[26] C. García-G, M.C. Jeziorski, C. Valverde-R, A. Orozco, Effects of iodothyronines on the hepatic outer-ring deiodinating pathway in killifish, Gen. Comp. Endocrinol. 135 (2) (2004) 201-209.

[27] A. Orozco, C. Valverde-R, Thyroid hormone deiodination in fish, Thyroid 15 (8) (2005) 799-813.

[28] W. Li, J. Zha, L. Yang, Z. Li, Z. Wang, Regulation of iodothyronine deiodinases and sodium iodide symporter mRNA expression by perchlorate in larvae and adult Chinese rare minnow (Gobiocypris rarus), Mar. Pollut. Bull. 63 (5-12) (2011) 350-355

[29] O. Marchand, R. Safi, H. Escriva, E. Van Rompaey, P. Prunet, V. Laudet, Molecular cloning and characterization of thyroid hormone receptors in teleost fish, J. Mol. Endocrinol. 26 (1) (2001) 51-65.

[30] J. Zha, Z. Wang, N. Wang, C. Ingersoll, Histological alternation and vitellogenin induction in adult rare minnow (Gobiocypris rarus) after exposure to ethinylestradiol and nonylphenol, Chemosphere 66 (3) (2007) 488-495.

[31] K.J. Livak, T.D. Schmittgen, Analysis of relative gene expression data using realtime quantitative PCR and the $2^{-\Delta \Delta C T}$ method, Methods 25 (4) (2001) 402-408.

[32] E. Rollerova, L. Wsolova, M. Urbancikova, Neonatal exposure to herbicide acetochlor alters pubertal development in female wistar rats, Toxicol. Mech. Methods 21 (5) (2011) 406-417.

[33] W. Li, J. Zha, Z. Li, L. Yang, Z. Wang, Effects of exposure to acetochlor on the expression of thyroid hormone related genes in larval and adult rare minnow (Gobiocypris rarus), Aquat. Toxicol. 94 (2) (2009) 87-93.

[34] Y. Jin, R. Chen, L. Wang, J. Liu, Y. Yang, C. Zhou, W. Liu, Z. Fu, Effects of metolachlor on transcription of thyroid system-related genes in juvenile and adult Japanese medaka (Oryzias latipes), Gen. Comp. Endocrinol. 170 (3) (2011) 487-493.

[35] S. Coleman, R. Linderman, E. Hodgson, R.L. Rose, Comparative metabolism of chloroacetamide herbicides and selected metabolites in human and rat liver microsomes, Environ. Health Perspect. 108 (12) (2000) 1151.

[36] H. Zheng, C. Ye, Photodegradation of acetochlor and butachlor in waters containing humic acid and inorganic ion, Bull. Environ. Contam. Toxicol. 67 (4) (2001) 601-608

[37] G. Stentiford, M. Longshaw, B. Lyons, G. Jones, M. Green, S. Feist, Histopathological biomarkers in estuarine fish species for the assessment of biological effects of contaminants, Mar. Environ. Res. 55 (2) (2003) 137-159. 
[38] D. Bernet, H. Schmidt, W. Meier, P. Burkhardt-Holm, T. Wahli, Histopathology in fish: proposal for a protocol to assess aquatic pollution, J. Fish Dis. 22 (1) (1999) 25-34.

[39] E. Lubzens, G. Young, J. Bobe, J. Cerdà, Oogenesis in teleosts: how fish eggs are formed, Gen. Comp. Endocrinol. 165 (3) (2010) 367-389.

[40] C. Rougeot, A. Krim, S. Mandiki, P. Kestemont, C. Mélard, Sex steroid dynamics during embryogenesis and sexual differentiation in Eurasian perch, Perca fluviatilis, Theriogenology 67 (5) (2007) 1046-1052.

[41] M.E. Burow, Y. Tang, B.M. Collins-Burow, S. Krajewski, J.C. Reed, J.A. McLachlan, B.S. Beckman, Effects of environmental estrogens on tumor necrosis factor $\alpha$ mediated apoptosis in MCF-7 cells, Carcinogenesis 20 (11) (1999) 2057-2061.

[42] E. Rollerova, Z. Gasparova, L. Wsolova, M. Urbancikova, Interaction of acetochlor with estrogen receptor in the rat uterus. Acetochlor-possible endocrine modulator?, Gen Physiol. Biophys. 19 (1) (2000) 73-84.

[43] V. Marlatt, C. Martyniuk, D. Zhang, H. Xiong, J. Watt, X. Xia, T. Moon, V. Trudeau, Auto-regulation of estrogen receptor subtypes and gene expression profiling of $17 \beta$-estradiol action in the neuroendocrine axis of male goldfish, Mol. Cell. Endocrinol. 283 (1) (2008) 38-48.

[44] C.D. Robinson, A.P. Scott, 5 Background document: fish vitellogenin (Vtg) as a biomarker of exposure to xenoestrogens, Integrated marine environmental monitoring of chemicals and their effects (2012) 30.

[45] Y. Liang, Z. Fang, Molecular cloning and mRNA expression of the vitellogenin and nuclear receptor gene induced by $17 \beta$-estradiol in the mud carp. Cirrhinus molitorella, Ecotoxicology 21 (3) (2012) 719-729.

[46] C. Liu, L. Yu, J. Deng, P.K. Lam, R.S. Wu, B. Zhou, Waterborne exposure to fluorotelomer alcohol 6:2 FTOH alters plasma sex hormone and gene transcription in the hypothalamic-pituitary-gonadal (HPG) axis of zebrafish, Aquat. Toxicol. 93 (2-3) (2009) 131-137.

[47] J.T. Sanderson, The steroid hormone biosynthesis pathway as a target for endocrine-disrupting chemicals, Toxicol. Sci. 94 (1) (2006) 3-21.
[48] K. Cheshenko, F. Brion, Y. Le Page, N. Hinfray, F. Pakdel, O. Kah, H. Segner, R.I Eggen, Expression of zebra fish aromatase cyp19a and cyp19b genes in response to the ligands of estrogen receptor and aryl hydrocarbon receptor, Toxicol. Sci. 96 (2) (2007) 255-267.

[49] D. Crump, K. Werry, N. Veldhoen, G. Van Aggelen, C.C. Helbing Exposure to the herbicide acetochlor alters thyroid hormone-dependent gene expression and metamorphosis in Xenopus laevis, Environ. Health Perspect. 110 (12) (2002) 1199-1205.

[50] A.O. Cheek, K. Kow, J. Chen, J.A. McLachlan, Potential mechanisms of thyroid disruption in humans: interaction of organochlorine compounds with thyroid receptor, transthyretin, and thyroid-binding globulin, Environ. Health Perspect. 107 (4) (1999) 273-278.

[51] H. Abe, Y. Oka, Mechanisms of neuromodulation by a nonhypophysiotropic GnRH system controlling motivation of reproductive behavior in the teleost brain, J. Reprod. Dev. 57 (6) (2011) 665-674.

[52] P. Roy, M. Datta, S. Dasgupta, S. Bhattacharya, Gonadotropin-releasing hormone stimulates thyroid activity in a freshwater murrel, Channa gachua (ham.), and Carps, Catla catla (ham.) and Cirrhinus mrigala (ham.), Gen. Comp. Endocrinol. 117 (3) (2000) 456-463.

[53] F. Qin, L. Wang, X. Wang, S. Liu, P. Xu, H. Wang, T. Wu, Y. Zhang, Y. Zheng, M. Li, Bisphenol A affects gene expression of gonadotropin-releasing hormones and type I GnRH receptors in brains of adult rare minnow Gobiocypris rarus, Comp. Biochem. Physiol. C: Toxicol. Pharmacol. 157 (2) (2012) 192-202.

[54] I. Swapna, B. Senthilkumaran, Thyroid hormones modulate the hypothalamohypophyseal-gonadal axis in teleosts: molecular insights, Fish Physiol Biochem. 33 (4) (2007) 335-345.

[55] A. Supriya, K. Raghuveer, I. Swapna, M. Rasheeda, T. Kobayashi, Y. Nagahama, A.D. Gupta, K. Majumdar, B. Senthilkumaran, Thyroid hormone modulation of ovarian recrudescence of air-breathing catfish Clarias gariepinus, Fish Physiol. Biochem. 31 (2-3) (2005) 267-270. 